\title{
On drying shrinkage in alkali-activated concrete: Improving dimensional stability by aging or heat-curing
}

\author{
R.J. Thomas, Diego Lezama, Sulapha Peethamparan* \\ Department of Civil and Environmental Engineering, Clarkson University, Potsdam, NY \\ 13676, USA
}

\begin{abstract}
The problem of excessive drying shrinkage in alkali-activated concrete (AAC) is well-documented in the literature. The magnitude of drying shrinkage is often three or more times that in portland cement concrete. This study investigates the effects of binder type, activator concentration, strength, age, and curing method on the manifestation of drying shrinkage in alkali-activated fly ash and slag cement concrete. Early-age shrinkage strains in excess of $1200 \mu \varepsilon$ (0.12 percent strain) are observed in AAC. This is attributed to delayed hydration, microstructure refinement, and strength development. The resulting damage is far more significant than in portland cement concrete. Shrinkage and resulting damage are greatly reduced when specimens are dried at later age and after heat-curing. Alkali-activated slag cement concrete is more sensitive to water loss than portland cement or alkali-activated fly ash concrete. This results from a finer pore structure in alkali-activated slag binders.

Keywords: Alkali-activated concrete, drying shrinkage, autogenous

\footnotetext{
*Corresponding author Tel: +1-315-268-4435

Email addresses: thomasrj@clarkson.edu (R.J. Thomas), lezamads@clarkson.edu (Diego Lezama), speetham@clarkson.edu (Sulapha Peethamparan )
}

Preprint submitted to Elsevier

October 1, 2016

(C) 2016. This manuscript version is made available under the Elsevier user license http://www.elsevier.com/open-access/userlicense/1.0/ 
shrinkage, fly ash, slag cement

\section{1. Introduction}

$2 \quad$ Alkali-activated fly ash and slag cement concrete are promising sustain3 able alternatives to ordinary portland cement concrete (PCC). The improved 4 sustainability of alkali-activated concrete (AAC) is based on: (1) The ben5 eficiation of industrial byproducts which would otherwise be landfilled, and 6 (2) the reduction of carbon emissions associated with portland cement pro7 duction. Estimates for the reduction in carbon emissions associated with 8 the use of alkali-activated or geopolymer binders in place of portland cement 9 vary wildly from $9 \%$ [1] to $80 \%$ [2], but most studies estimate a reduction of

at least $40 \%$ [2-7]. The reduction in emissions is not only dependent on the chemistry of the alkaline activator, but also on the availability of raw materials, fuel costs, and the efficiency of the clinkering operation in a particular geographical location. This provides some context for the lack of consensus within the literature.

Although alkaline activation of aluminosilicates is by no means a new technology [8 12, alkali-activated fly ash (AAF) and slag cement (AASC) binders have only recently emerged as viable alternatives to portland cement. A number of studies describe the activation chemistry, product formation, reaction kinetics, and mechanical properties of AAF and AASC concrete [13 22]. Despite this, the long-term durability of AAC is not summarily proven [12, 23 25]. Several questions remain with regard to the durability of AAC. These mainly relate to carbonation, chloride permeability, alkalisilica reactivity, resistance to chemical attack, and shrinkage. This study 
investigates the last.

\subsection{Drying and autogenous shrinkage}

Volume instability in hardened cement or concrete may occur due to carbonation, thermal effects, drying, or self-dessication. The latter two are of concern for the present study. Drying and autogenous shrinkage both result from the removal of pore water from within the hardened binder. The former is due to the loss of internal water to the external environment through evaporation. The latter is due to self-dessication, i.e., the consumption of pore water by the continuing hydration reaction. Only autogenous shrinkage can occur if the specimen is sealed to prevent moisture egress, but autogenous and drying shrinkage occur simultaneously if the specimen is unsealed.

Drying shrinkage is approximately proportional to water loss [26]. Since aggregates are highly dimensionally stable, shrinkage is dominant within the binder paste. An increase in binder content in concrete, which leads to an increase in the paste volume, naturally leads to an increase in drying shrinkage [27, 28]. With sufficient shrinkage strains, cracking occurs. This can result in weakening of concrete structures, but the formation of cracks is more significant to the durability of concrete [28].

Since autogenous shrinkage results from the consumption of water by the continuing hydration reaction, it is only of concern when the binder does not reach its full hydration potential. In the case of portland cement, complete hydration requires $w / \mathrm{cm}>0.42$ [29 31]. Above this value, at which sufficient water is provided for complete hydration, autogenous shrinkage is theoretically nonexistent. It should be noted that there is some disagreement on the value of $w / \mathrm{cm}$ which results in complete hydration of portland 
cement [32, 33], but this is of no consequence to the present study.

Three predominate mechanisms are known to contribute to drying shrinkage: Surface energy, capillary stress, and disjoining pressure [34 41]. The effects of surface energy (or surface tension) are explained by the Bangham equation and Gibb's free energy [35, 40, 42, 43], which describe the shrinkage resulting from a reduction in surface energy due to the spreading of physically adsorbed water within the pore volume. Surface energy effects are significant below $45 \% \mathrm{RH}$ [44]. Disjoining pressure arises from a cohesive interaction-mainly due to Van der Waals forces-between the pore water and the surface within the pore volume [40, 45, 48]. Disjoining pressure is significant only above $45 \% \mathrm{RH}[44]$.

Shrinkage induced by capillary stresses is a function of the volume of capillary pores, the capillary stress, and the compliance of the medium [49]. The volume of capillary pores in PCC is sensitive to $w / \mathrm{cm}$ and the degree of hydration [34, 50, 51]. The capillary pressure $P_{\text {cap }}$ is related to the surface tension of the pore fluid $\gamma$ and the pore radius $r$ according to Equation 1 [44, 52,53 .

$$
P_{c a p}=\frac{2 \gamma}{r}
$$

${ }_{66}$ As the surface tension increases, so does the capillary pressure. Larger pores develop lower capillary stresses since the ratio of pore volume to surface area is lower. Capillary stresses are significant only above $45 \% \mathrm{RH}$ due to instability of menisci below this humidity level [44. 


\subsection{Drying and autogenous shrinkage in $A A C$}

The problem of excessive drying shrinkage strains in AASC is well documented [12, 14, 54, 62]. Bakharev et al. [55] showed that curing at elevated temperature effectively reduced the magnitude of drying shrinkage strain in AASC concrete. Additions of gypsum, common air-entraining admixtures (AEA), and shrinkage-reducing admixtures (SRA) have also been shown to temper the magnitude of drying shrinkage in AASC [57, 59]. Atiş et al. 61] found that the use of sodium carbonate as an activator instead of sodium silicate or sodium hydroxide also resulted in reduced shrinkage. Several studies have also demonstrated increased autogenous shrinkage in AASC relative to comparable portland cement [55, 57, 60, 62].

In accordance with the previous discussion, the pore structure has a significant effect on drying shrinkage in concrete. Collins and Sanjayan [58] attributed the increased drying shrinkage in AASC concrete to a finer overall porosity. AASC binders are known to include a higher percentage of mesopores $(2 \mathrm{~nm} \leq r \leq 50 \mathrm{~nm})$ than portland cement [58, 63, 65]. Shi 63 ] posited that sodium silciate-activated slag cement binders resulted in the finest pore structure of any AASC binders. Bakharev et al. 55. showed that the relatively localized hydration in heat-cured AASC resulted in a coarser porosity. Reduced drying shrinkage in heat-cured AASC concrete was attributed to this change in pore structure [55]. Furthermore, Palacios and Puertas [59] attributed reduced drying shrinkage in AASC with SRA to a coarsening of the pore structure and a reduction in pore fluid surface tension.

Comparatively few studies have discussed the manifestation of drying or autogenous shrinkage in AAF. Fernández-Jiménez et al. [66] reported that 
the drying shrinkage in AAF mortar was less than that observed in comparable OPC mortar. Several studies have reported similar results for fly ash-based geopolymer binders [67, 68], but geopolymers are chemically and mechanically distinct from AAF binders. In a study of the properties of alkali-activated blended fly ash/slag cement mortars, Chi and Huang [69] showed that a higher proportion of fly ash led to a decrease in the observed drying shrinkage strain. That same study also indicated that an increase in the dosage of sodium oxide in blended alkali-activated binders led to a decrease in the observed shrinkage [69].

The porosity and pore size distribution in alkali-activated binders has been studied somewhat intensely using micro-computed tomography $(\mu \mathrm{CT})$, mercury intrusion porosimmetry (MIP), Wood's metal intrusion porosimmetry (WMIP), nitrogen sorption, water sorption, and microscopy; much of this research is neatly summarized by Provis et al. 70. The high degree of heterogeneity and chemical complexity of alkali-activated binders results in a wide distribution of pore sizes, which can range from the order $10 \mathrm{~nm}$ to the order $10 \mu \mathrm{m}$ [70]. As a result of very small pore sizes and the inkbottle effect, standard techniques like MIP, WMIP, and water sorption give incomplete information regarding the porosity and pore structure in alkaliactivated binders [70 73]. More advanced techniques like $\mu \mathrm{CT}$ and nitrogen adsorption using Brunauer-Emmet-Teller (BET) theory [74] give more complete information.

Very high porosity has been observed in AAF binders [75 78], which are devoid of large capillary pores but include some very large cavities [78]. In comparison, the pore structure of AASC binders is much finer and more 
tortuous [70]. Some conflicting results have indicated only minor differences in the porosity and pore structure with curing time [79], but most studies suggest that the porosity and pore connectivity in AAC decrease with both curing time and curing temperature [70, 78, 80, 81].

\subsection{Research objectives}

The problem of excessive drying shrinkage in AASC concrete is welldocumented. However, there is limited information about how the activator concentration in AAC affects the susceptibility to drying shrinkage. The effect of heat curing on the manifestation of drying shrinkage has been documented to some extent, but the effect of age at drying has not. Finally, the damage that occurs as a result of drying shrinkage in AAC has not been fully investigated. This study seeks to address these gaps in knowledge.

\section{Materials and methods}

\subsection{Materials and mixture proportions}

The binder materials used in this study were class $\mathrm{C}$ fly ash meeting the specifications of ASTM C618, grade 100 ground granulated blast-furnace slag (slag cement) meeting the specifications of ASTM C989, and Type I ordinary portland cement (OPC) meeting the specifications of ASTM C150. The oxide composition of the fly ash and slag cement is listed in Table 1 .

The activator was an aqueous sodium silicate solution $\left(\mathrm{Na}_{2} \mathrm{O}+m \cdot \mathrm{SiO}_{2}\right)$. The silica modulus $m$ is the mass ratio of silica to sodium oxide in the activating solution. Activator concentrations were specified by the silica modulus $m$ and the dosage of sodium oxide in percent by mass of binder. 
The solution-to-binder ratio $s / b$ is the mass ratio of activator solution (or water, in the case of OPC concrete) to binder. The solution-to-binder ratio $s / b$ was 0.40 throughout. Activator concentrations are given in Table 2. The fine aggregate was a natural quartz sand. The specific gravity was 2.71 and the fineness modulus was 2.36. The coarse aggregate was a quarried crushed stone composed mainly of rose quartz. The nominal maximum aggregate size was $12.5 \mathrm{~mm}$ (0.5 in). The binder content was $570 \mathrm{~kg} / \mathrm{m}^{3}$, the coarse aggregate content was $780 \mathrm{~kg} / \mathrm{m}^{3}$, the fine aggregate content was $658 \mathrm{~kg} / \mathrm{m}^{3}$, and the activator solution content was $228 \mathrm{~kg} / \mathrm{m}^{3}$.

For comparative purposes, an effort was made to replicate the activator concentrations used for fly ash mixtures (FC1-FC3) using slag cement as the binder. The solutions concentrations for FC1 and FC2 are thus replicated for $\mathrm{SC} 1$ and $\mathrm{SC} 2$. The solution concentration used for $\mathrm{FC} 3$ (i.e., $6 \% \mathrm{Na}_{2} \mathrm{O}$, $m=1.5)$ resulted in a mixture that was poorly workable and difficult to consolidate when used with slag cement as the binder, and was therefore excluded.

\subsection{Experimental methods}

Concrete was cast into $\phi 101.6 \mathrm{~mm}$ x $203.2 \mathrm{~mm}(\phi 4$ in $\mathrm{x} 8$ in) cylinders for the determination of compressive strength and $50.8 \times 50.8 \mathrm{~mm}$ ( $2 \times 2$ in) mortar bars with gage length $254 \mathrm{~mm}$ (10 in) for shrinkage evaluation. The latter were in accordance with the specifications of ASTM C157. Specimens were cast in three equal lifts and consolidated between lifts using a vibrating table. Cast specimens were double-sealed with plastic film to limit moisture loss. Moist-cured specimens were stored at $23 \pm 2{ }^{\circ} \mathrm{C}$ and $>95 \%$ RH. Heatcured specimens were stored in an oven at $50 \pm 0.1^{\circ} \mathrm{C}$. Compressive strength of 
Table 1: Oxide composition of binders

\begin{tabular}{|l|cc|}
\hline & $\begin{array}{l}\text { Slag cement } \\
\text { (percent composition by mass) }\end{array}$ & Fly ash \\
\hline $\mathrm{SiO}_{2}$ & 36.0 & 37.7 \\
$\mathrm{Al}_{2} \mathrm{O}_{3}$ & 10.5 & 20.0 \\
$\mathrm{CaO}$ & 39.8 & 23.4 \\
$\mathrm{MgO}$ & 7.9 & 4.3 \\
$\mathrm{Na}_{2} \mathrm{O}$ & 0.3 & 1.7 \\
$\mathrm{SO}_{3}$ & 2.1 & 2.4 \\
$\mathrm{~K}_{2} \mathrm{O}$ & 0.2 & 0.6 \\
$\mathrm{Fe}_{2} \mathrm{O}_{3}$ & 0.7 & 5.6 \\
$\mathrm{LOI}$ & 0.0 & 0.31 \\
\hline
\end{tabular}

moist-cured concrete was evaluated at 1, 3, 7, 14, 28, and $90 \mathrm{~d}$. Compressive strength of heat-cured concrete was evaluated at 24, 48, and $72 \mathrm{~h}$. Each compressive strength test included a minimum of four replicates.

Since alkali-activated binders have exhibited slow hydration and strength gain (depending on activator composition and concentration) [82 84], moistcured shrinkage specimens remained in their molds for $72 \mathrm{~h}$, instead of the standard $24 \mathrm{~h}$ as prescribed by ASTM C157. Heat-cured shrinkage specimens were demolded after $48 \mathrm{~h}$. Following demolding, the initial length, mass, and dynamic modulus of elasticity of each specimen was measured. Specimens were then submerged in saturated limewater for either $72 \mathrm{~h}$ or $90 \mathrm{~d}$. Following the saturation period, the specimen length, mass, and dynamic modulus of elasticity were again measured. Specimens were then dried on stainless steel 
Table 2: Mixture proportions and activator solution concentrations (Note: PC indicates portland cement, FC indicates fly ash, and SC indicates slag cement)

\begin{tabular}{|l|ccc|}
\hline ID & \multicolumn{3}{|c|}{ Activator } \\
& $\% \mathrm{Na}_{2} \mathrm{O}$ & $m$ & $s / b$ \\
\hline PC1 & - & - & 0.4 \\
\hline FC1 & 4.0 & 1.5 & 0.4 \\
FC2 & 5.0 & 1.5 & 0.4 \\
FC3 & 6.0 & 1.5 & 0.4 \\
\hline SC1 & 4.0 & 1.5 & 0.4 \\
SC2 & 5.0 & 1.5 & 0.4 \\
SC3 & 4.0 & 0.75 & 0.4 \\
SC4 & 5.0 & 0.75 & 0.4 \\
SC5 & 6.0 & 0.75 & 0.4 \\
\hline
\end{tabular}


wire racks at $50 \pm 5 \% \mathrm{RH}$ and $22 \pm 2{ }^{\circ} \mathrm{C}$ to ensure equal drying on all sides. Measurements of length, mass, and dynamic modulus of elasticity in drying specimens were taken daily for one week, and then at 14, 28, 56, 90, 180, 270, and 365 d. Several cylindrical specimens were exposed to identical conditions and the compressive strength of those specimens was measured after drying for $90 \mathrm{~d}$.

For the sake of clarity in the following discussion, some nomenclature is defined. Specimens which were moist-cured for $72 \mathrm{~h}$ and submerged in saturated limewater for $48 \mathrm{~h}$ prior to drying are said to be dried at early age. Specimens which were moist-cured for $72 \mathrm{~h}$ and submerged in saturated limewater for $90 \mathrm{~d}$ prior to drying are said to be dried at later age. Finally, specimens which were heat-cured for $48 \mathrm{~h}$ and submerged in saturated limewater for $48 \mathrm{~h}$ prior to drying are said to be dried after heat-curing.

Compressive strength was evaluated in accordance with the specifications of ASTM C39. Drying shrinkage was measured as length change relative to the initial specimen length in accordance with the specifications of ASTM C596. Specimen length was measured using a standard length comparator and invar reference rod in accordance with the specifications of ASTM C490. Dynamic modulus of elasticity $E_{d}$ was determined from Equation 2, where $C$ is a geometric factor found from ASTM C215, $M$ is the specimen mass, and $n$ is the fundamental transverse resonant frequency.

$$
E_{d}=C M n^{2}
$$




\section{Results and Discussion}

\subsection{Drying shrinkage}

\subsubsection{Early-age drying shrinkage}

The drying shrinkage strain and water loss in specimens dried at early age are plotted in Figures 1 and 2 for AAF and AASC concrete, respectively. Drying shrinkage in PCC occurred gradually, reaching a terminal value of about $700 \mu \varepsilon$ (0.07 percent strain). The accompanying water loss was about 2.7 percent by mass. About half the total shrinkage was observed in the first $7 \mathrm{~d}$. This is consistent with expectations based on existing literature 14, 54,62].

The drying shrinkage in AAF concrete was much greater, in the range of 800-1300 $\mu \varepsilon(0.08-0.13$ percent strain). Additionally, that shrinkage occurred much more rapidly. This is in contrast to previously reported results [66, 69]. More than 90 percent of the ultimate shrinkage value was observed in the first $7 \mathrm{~d}$, with about half in the first $24 \mathrm{~h}$. A high degree of dimensional stability was reached within $90 \mathrm{~d}$. The magnitude of shrinkage decreased as the sodium oxide dosage in the activator increased, which follows Chi and Huang [69]. Increased sodium oxide concentration improves compressive strength and modulus of elasticity within the represented range, and has also been shown to reduce porosity in AAC [54, 58, 59, 63, 82, 85, 86]. A stiffer and less porous concrete will logically be more dimensionally stable.

The water loss in AAF concrete was similarly high, in the range of 3-6 percent by mass. Most of the water loss was at early age, and the shrinkage strain showed a direct correlation to the water loss. Much more water was lost from AAF concrete than PCC, which suggests that the availability of 
water for evaporation is higher in AAF. Since it is known that the total porosity in AAF binders is relatively high, this logically follows.

The drying shrinkage strain in AASC concrete was also very high. The rate of shrinkage was faster than in PCC, but not quite as fast as in AAF concrete. About two-thirds the ultimate shrinkage was realized within $7 \mathrm{~d}$. Although the magnitude of shrinkage strain was higher in AASC concrete than in PCC, the water loss was about half or less. Furthermore, the water loss was not directly related to the shrinkage strain in AASC concrete. For example, the shrinkage strain was greater in mixture $\mathrm{SC} 2$ than in $\mathrm{SC} 1$, but less water was lost. The magnitude of shrinkage is normally well-correlated to the percent water loss [26]. Both of these conclusions are therefore somewhat counter-intuitive.

The observed shrinkage was higher in magnitude when the silica modulus increased from 0.75 to 1.5 . With constant silica modulus, the magnitude of shrinkage increased with sodium oxide concentration. Increases in both silica modulus and sodium oxide are known to improve the strength and stiffness of AASC concrete within the represented range [54, 61, 63, 85, 86]. Sodium oxide tends to accelerate activation, while silica tends to retard it $82,84,87-$ 90]. If changes in the mechanical properties (strength, stiffness, or compliance) were responsible for the observed shrinkage reduction then increased sodium oxide or silica modulus would be expected to result in lower shrinkage. However, mixtures with higher sodium oxide and silica modulus actually experienced higher-magnitude shrinkage. It is therefore likely that changes in porosity or the pore structure are a more likely culprit. In fact, Collins and Sanjayan [58] argued that the pore structure was more important in 


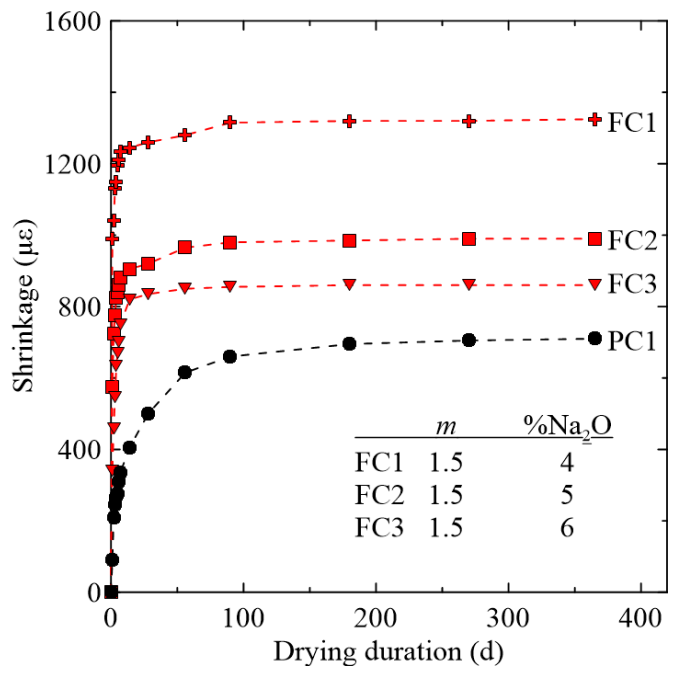

(a) Drying shrinkage

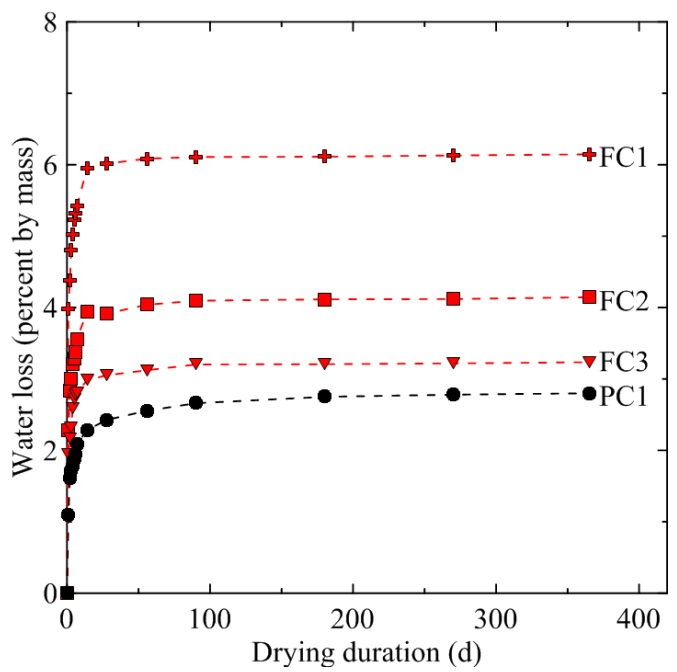

(b) Water loss

Figure 1: Early-age drying shrinkage and water loss in AAF concrete

determining the shrinkage in AASC concrete than the water loss. Shi 63 showed that when silica was included in the alkaline activator, the pore structure in AASC binders became much finer. The increased shrinkage in AASC concrete with higher silica modulus must therefore result from a finer pore structure. In accordance with Equation 1, this increases the capillary tensile stress. In addition, this makes diffusion through the binder matrix more difficult.

\subsubsection{Later-age and heat-cured drying shrinkage}

Drying shrinkage strains and water loss in specimens dried at later age and after heat-curing are plotted in Figures 3 and 4 . Drying shrinkage in AAC at later age was much less than at early age. The maximum shrinkage strain recorded in AAC at later age was about $500 \mu \varepsilon$ (0.05 percent). That 


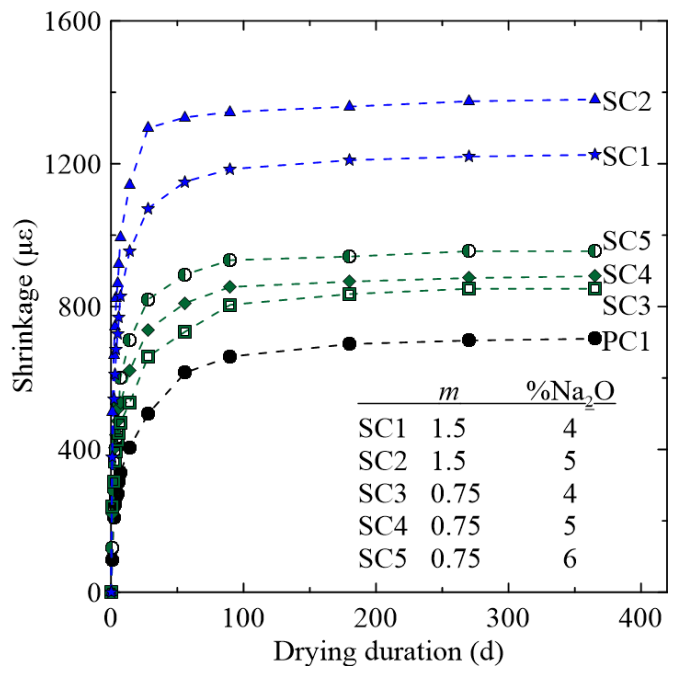

(a) Drying shrinkage

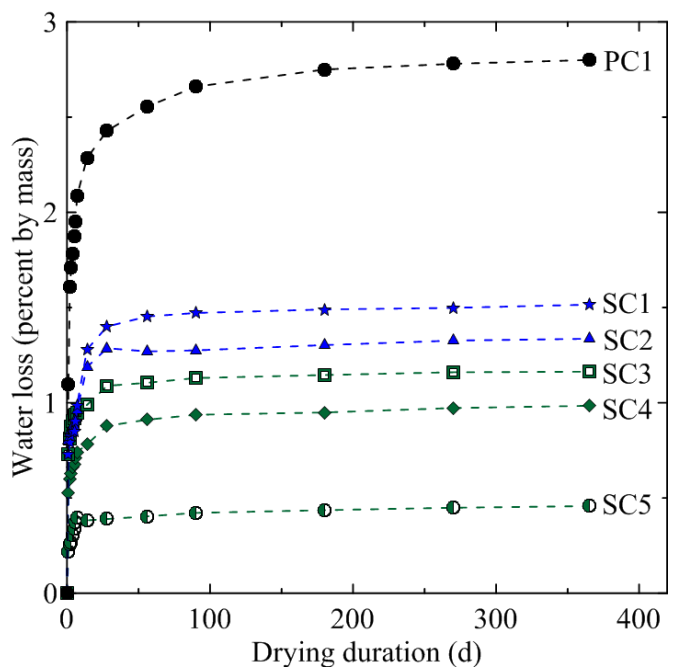

(b) Water loss

Figure 2: Early-age drying shrinkage and water loss in AASC concrete

shrinkage was still far more rapid in AAC than in PCC, especially for AAF concrete. The shrinkage was slightly reduced in PCC at later age, but only by a small margin. The water loss in PCC and AAF concrete was approximately the same as at early-age, but was greatly reduced in AASC concrete. Since there was little change in water loss in AAF concrete, the change in shrinkage must arise from some change in the pore structure or mechanical properties. The strength at $90 \mathrm{~d}$ is much higher than at $3 \mathrm{~d}$, and the stiffness is known to follow the strength 86. In addition, some significant changes in the microstructure can be expected after $3 \mathrm{~d}$ due to the relatively slow kinetics of the activation reaction $82,84,87,90]$. A dramatic reduction in water loss is at least partially responsible for the reduction in shrinkage in AASC concrete, but it is very likely that changes in mechanical properties and porosity also contribute. The microstructure of AASC binders are known to experience 
gradual refinement $82,84,87,90$, . Reduced water loss is therefore a likely result of lesser total porosity at later age [70, 81]. This limits the pore volume and therefore the water within the pore structure.

At elevated temperature, the reduction in shrinkage is even greater. The maximum drying shrinkage observed in AAC cured at elevated temperature was about $350 \mu \varepsilon$ (0.035 percent). The water loss in AAF concrete was approximately the same as under ambient curing at early age and at later age. The water loss was greatly reduced in AASC concrete, which is again likely a result of a lower total porosity. Hydration, and therefore refinement of the microstructure, are of course greatly accelerated at elevated temperature 82 84, 90]. Significant strength development can then be expected in AAC even when heat-cured for shorter durations. It is therefore likely that the benefits of heat-curing in terms of shrinkage mitigation could be realized even under heat-curing regimes of much shorter duration than those employed here.

It is also important to consider the changes in product phase composition that occur in AAF and AASC binders with age. Portland cement binders are very stable in phase composition, and reach that stability fairly early in the curing period. Alkali-activated binders, on the other hand, are known to change in both composition and concentration throughout their curing period. Furthermore, the product phase composition in alkali-activated binders may be significantly altered by carbonation, efflorescence, or other phenomena [23, 91 93]. These changes in phase composition may also have a significant effect on the water loss and resulting shrinkage.

Some limited information regarding the water-permeable porosity of AAC mixtures identical to those discussed in this paper has been presented by some 


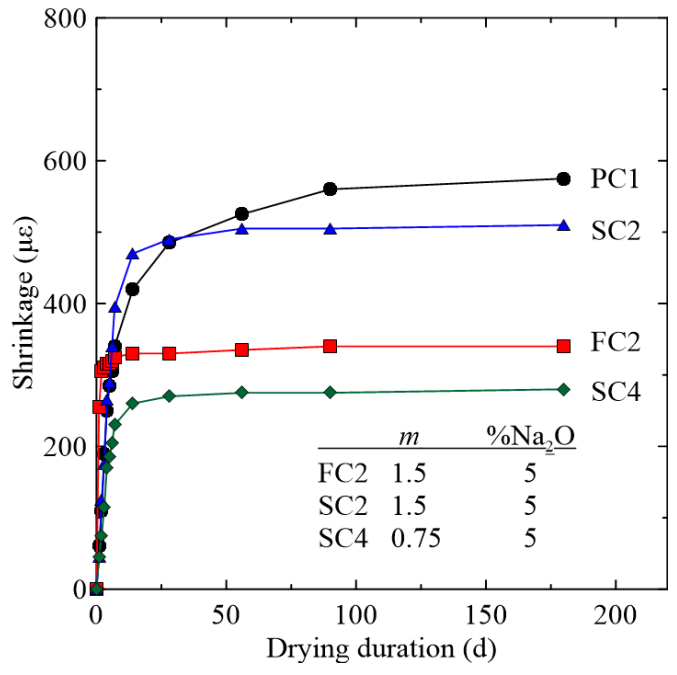

(a) Drying shrinkage

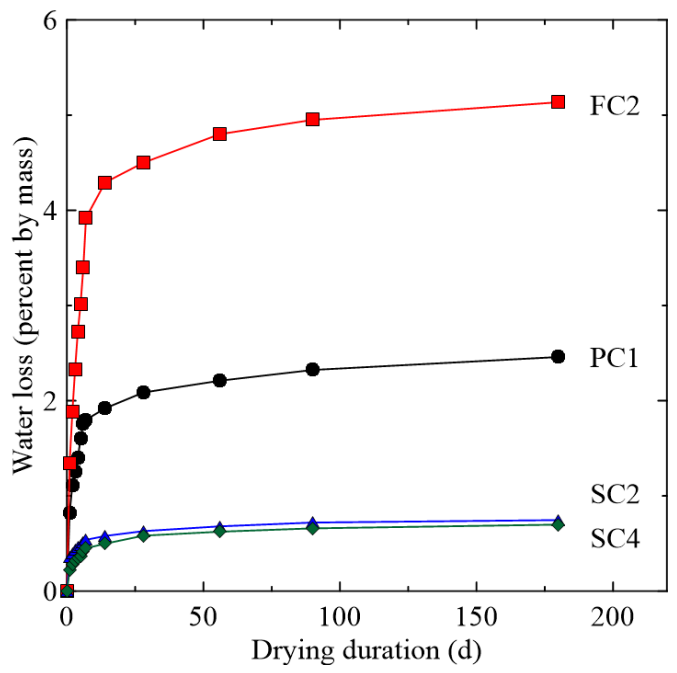

(b) Water loss

Figure 3: Shrinkage and water loss after $90 \mathrm{~d}$ limewater curing

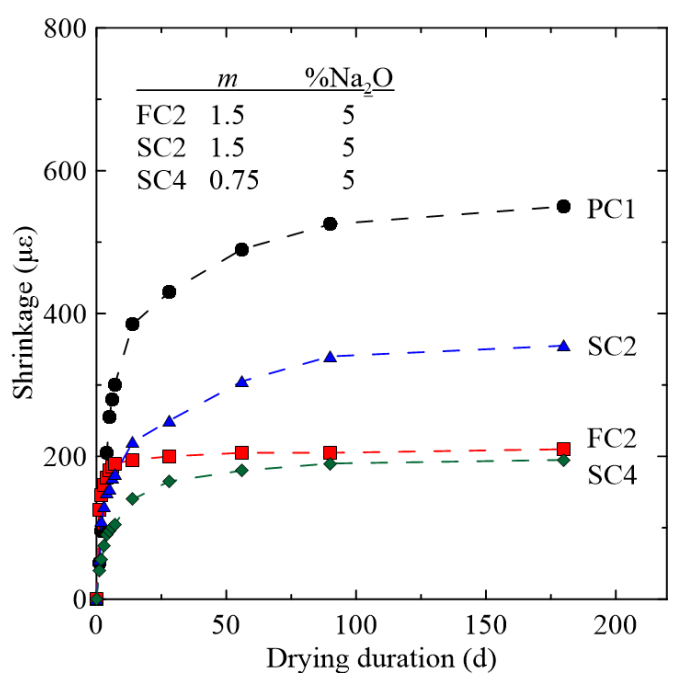

(a) Drying shrinkage

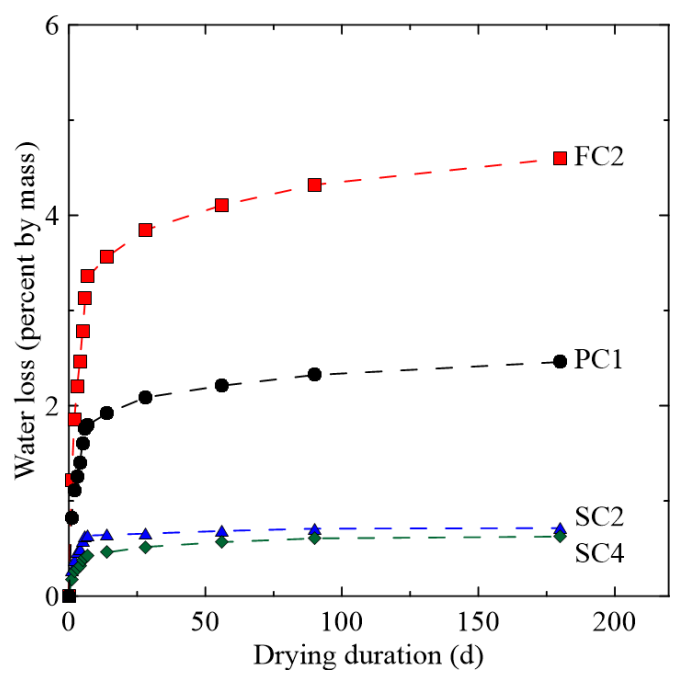

(b) Water loss

Figure 4: Shrinkage and water loss after $48 \mathrm{~h}$ heat curing 
of the authors [94, 95]. The water-permeable porosity and accompanying electrical conductivity data indicate that the porosity and pore connectivity and AAS is significantly lower when slag cement is used as the binder. Furthermore, these data indicate that heat-curing tends to reduce the permeable porosity and reduce the electrical conductivity, suggesting a net reduction in porosity and pore connectivity. Although these data are an admittedly poor description of the pore structure in AAC, they do give some context for the above discussion. Furthermore, a few previous studies by other authors have reported on the pore structure of similar concrete mixtures. In particular, Provis et al. [70] reported on the porosity and tortuosity of the pore network in sodium metasilicate-activated binders made with fly ash, slag cement, and blends thereof using three-dimensional $\mu \mathrm{CT}$ mapping of the pore structure. That study indicated a significantly lower porosity and high tortuosity in AASC binders than in AAF; longer curing times were shown to decrease the porosity and increase the tortuosity in both AAF and AASC binders [70]. Sindhunata et al. [79] reported contrary results for fly ash-based geopolymers based on nitrogen adsorption, indicating only a slight reduction in porosity with increased curing time. A few other studies have shown decreased porosity and pore connectivity in AAF and AASC binders with increased curing temperature or curing duration [78, 80, 81, 96]. These results are mostly consistent with the above arguments.

\subsubsection{Sensitivity to water loss}

The sensitivity of length change to water loss at early age, late age, and after heat curing is shown in Figure 5. Here, we define sensitivity as the slope of the curve where the abscissa is water loss and the ordinate is shrinkage, 
i.e., the length change per unit water loss. Evaluating the sensitivity provides clues about the mechanism involved in changes in shrinkage. Since the capillary tensile stress, and therefore the magnitude of shrinkage resulting from a unit water loss, is dependent on the pore radius, a change in sensitivity suggests a change in the pore size distribution. Increased sensitivity suggests a finer porosity, while decreased sensitivity suggests a coarser porosity.

The sensitivity of PCC was about the same at early and later age. At early age, the sensitivity of AAF concrete was about the same as that of PCC. This suggests that the pore size distribution was relatively similar. This is in good agreement with existing literature [75] 78]. The increased shrinkage in AAF concrete dried at early age therefore resulted from increased water loss. It is known that the total porosity in AAF concrete is very high [75-78], allowing for more water absorption during saturation and more water loss during drying.

The sensitivity of AAF concrete was reduced at later age and after heatcuring, although the water loss was not greatly affected. It has been suggested that both the porosity and pore size in AAF binders are reduced with age and under heat-curing [78]. The minimal reduction in water loss observed here suggests only a minor reduction in porosity. The reduced sensitivity suggests a coarsening of the pore structure, rather than the expected refinement. It has been shown that AAF binders are highly susceptible to microcracking, particularly when heat-cured [82]. In fact, micrographs of similar binder systems (except with higher $s / b$ ) presented by Deir et al. [82] show abundant microcracking, particularly when heat-cured. The presence of microcracks could account for this reduced sensitivity, since water lost from 
very fine microcracks would not likely generate appreciable stress. Additionally, the drastic improvement in strength in AAF concrete at later age and after heat-curing is accompanied by a likewise improvement in the modulus of elasticity [86]. This results in a stiffer concrete which is more resistant to length change as a result of internal stresses.

Length change in AASC concrete was more sensitive to water loss than PCC and AAF concrete under all curing conditions. Not only is the porosity in AASC concrete generally less than that of PCC, the pore structure is finer [55, 58, 59, 63, 65, 85]. This is likely the reason for the increased sensitivity to water loss observed in AASC concrete. The sensitivity was similar when dried at early age, later age, and after heat-curing. Reduced shrinkage under the latter two conditions is therefore a result of reduced water loss. This is in agreement with previous observations which indicate a reduction in total porosity in AASC concrete at later age and after heat-curing [55].

\subsubsection{Ultimate shrinkage}

The ultimate drying shrinkage is that value at which the shrinkage measurement stabilized, i.e., did not change by more than $0.0025 \mathrm{~mm}$ (0.0001 in) between successive readings. All specimens reached this point within one year. The ultimate drying shrinkage values in AAC and PCC are compared in Table 3. The table lists the ultimate drying shrinkage for specimens dried at early age, later age, and after heat-curing. The ultimate drying shrinkage for PCC dried at early age was only marginally higher than under other conditions. This indicates that aging PCC or curing at elevated temperature did little to improve resistance to drying shrinkage. On the contrary, the terminal early-age drying shrinkage in $\mathrm{AAC}$ was three to five times that at later 


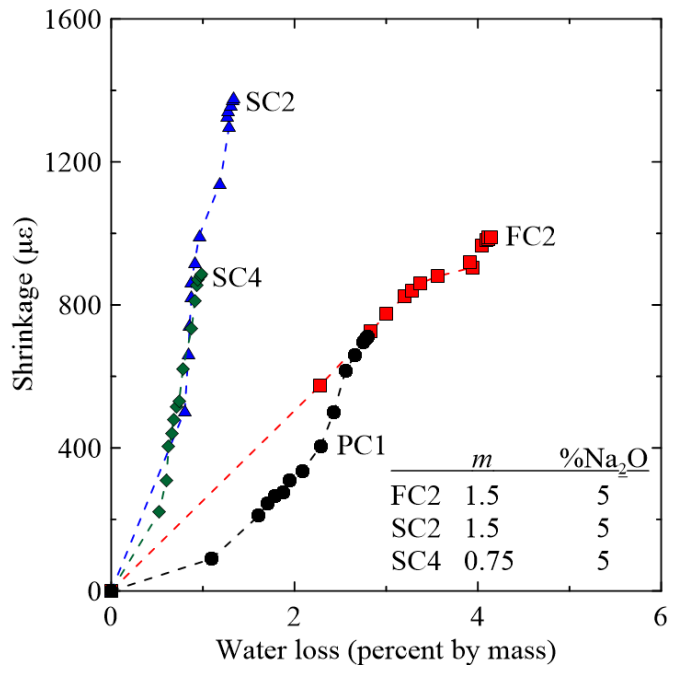

(a) After $48 \mathrm{~h}$ limewater curing

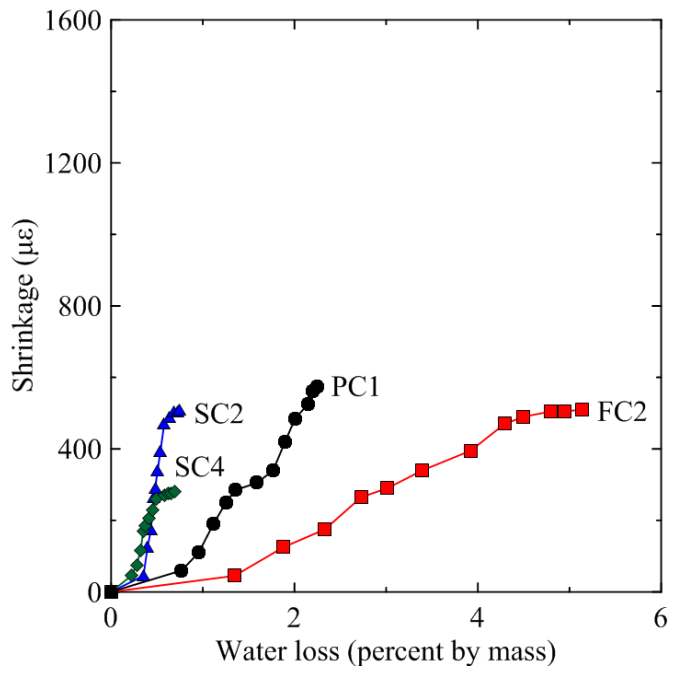

(b) After $48 \mathrm{~h}$ heat curing

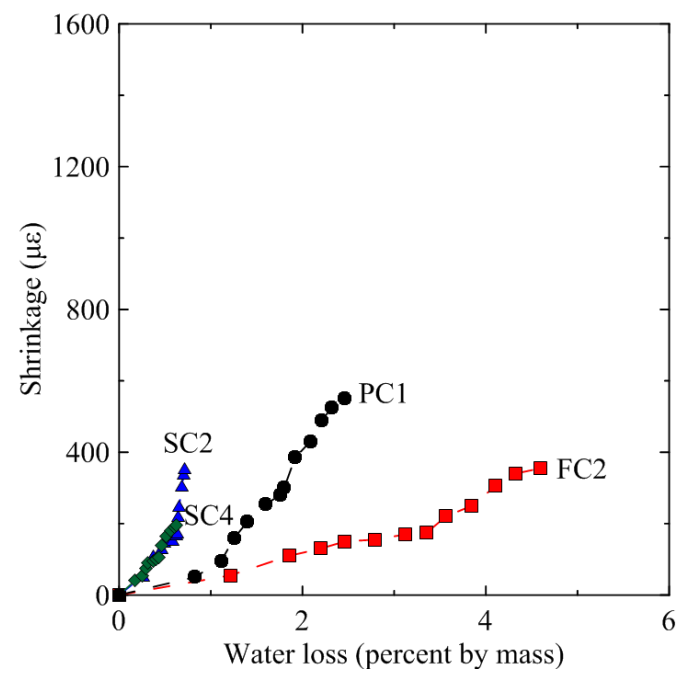

(c) After $90 \mathrm{~d}$ limewater curing

Figure 5: Sensitivity of length to water loss under varying curing conditions 
Table 3: Terminal drying shrinkage values for specimens dried at early and late ages. *Ratio refers to the ratio of late-age or heat-cured drying shrinkage to early-age drying shrinkage

\begin{tabular}{|c|ccc|}
\hline & \multicolumn{3}{|c|}{ Ultimate drying shrinkage $(\mu \varepsilon)$} \\
\hline Mixture & Early-age & $\begin{array}{c}\text { Late-age } \\
\left({ }^{*} \text { Ratio }\right)\end{array}$ & $\begin{array}{c}\text { Heat-cured } \\
\left({ }^{*} \text { Ratio }\right)\end{array}$ \\
\hline PC1 & 710 & 575 & 550 \\
& & $(0.81)$ & $(0.77)$ \\
\hline FC2 & 975 & 340 & 210 \\
& & $(0.35)$ & $(0.22)$ \\
\hline SC2 & 1380 & 510 & 355 \\
& & $(0.37)$ & $(0.26)$ \\
\hline SC4 & 890 & 280 & 195 \\
& & $(0.31)$ & $(0.22)$ \\
\hline
\end{tabular}

age or after heat-curing. Therefore, both heat-curing and aging effectively reduced the susceptibility of AAC to drying shrinkage. The former is more effective by a noticeable margin. This again likely results of the documented improvements in porosity at later age and after heat-curing [55].

\subsection{Damage during drying}

Damage in concrete due to drying shrinkage occurs mainly due to cracking. Typical cracking patterns for AAF and AASC concrete dried for $90 \mathrm{~d}$ at early age and after heat-curing are shown in Figure 6. Specimens were dusted with blue chalk to highlight the appearance of cracks. Cracking was much more severe in AAF concrete, especially when dried at early age. Only 


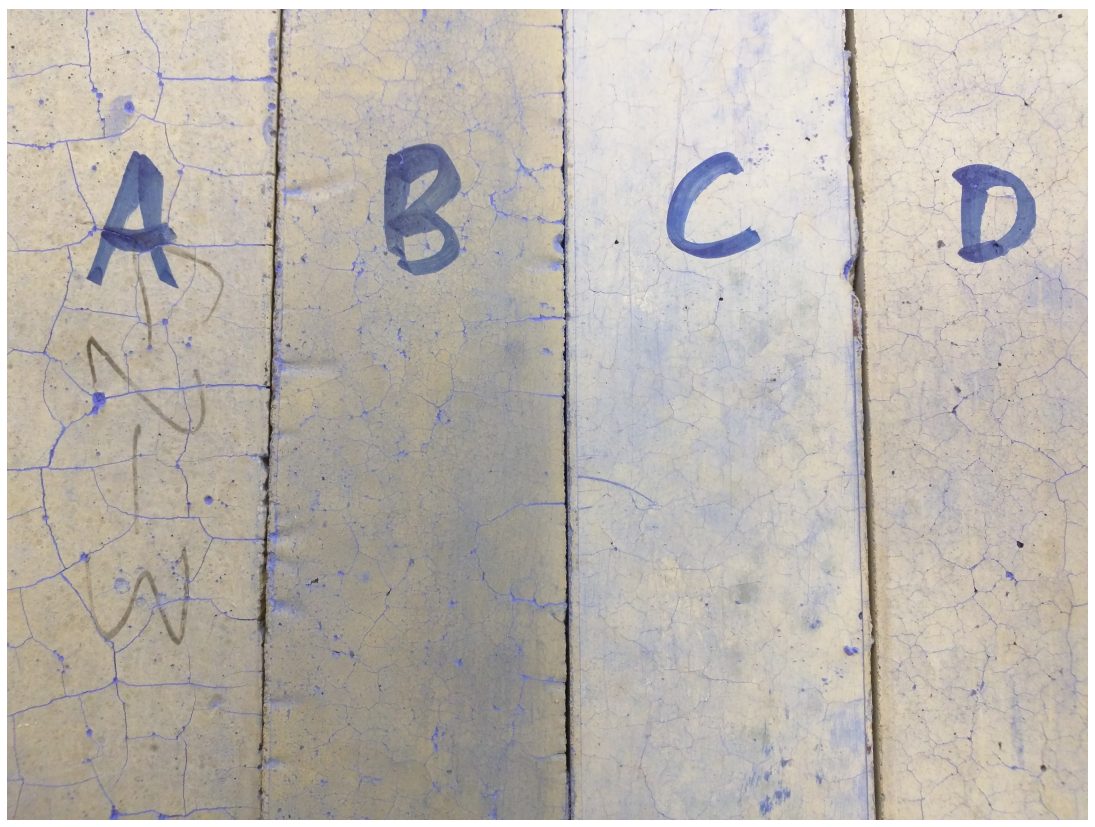

Figure 6: Typical cracking patterns in (a) AAF concrete dried at early age, (b) AAF concrete dried after heat-curing, (c) AASC concrete dried at early age, and (d) AASC concrete dried after heat-curing

very minor surface cracks were observed in AASC concrete, despite some very large drying shrinkage strains observed. Specimens dried after heat curing exhibited some significant surface cracking, despite minimal drying shrinkage strain. These cracks were visible immediately after heat curing and prior to drying. This suggests that the cracking occurred during heat-curing, indicating that some autogenous or drying shrinkage must be occurring during the initial curing period.

Cracking reduces both the compressive strength and the dynamic modulus of elasticity in concrete. The extent of damage can therefore be evaluated by measuring both properties before, during, and after drying. Baseline strength values are listed in Table 4 for moist-cured and heat-cured cylin- 
ders. The $28 \mathrm{~d}$ moist-cured compressive strengths of all concrete mixtures used in this study are presented in Table 4 . The compressive strength of AAF concrete was greatly improved by curing at elevated temperature for $48 \mathrm{~h}$. The compressive strength of AASC concrete was approximately equivalent under both curing conditions. The compressive strength of PCC after $48 \mathrm{~h}$ heat-curing was not recorded. Although PCC does gain appreciable strength in $48 \mathrm{~h}$ at $50{ }^{\circ} \mathrm{C}$, the strength gain is not accelerated nearly as much as in AAC.

The strength development of selected mixtures is shown in Figure 7 . Strength gain in AAC at ambient temperature is slower than in PCC, particularly for AAF concrete. The $1 \mathrm{~d}$ compressive strength of PCC is about one-third the strength at $28 \mathrm{~d}$. AASC concrete develops strength relatively slowly. The $1 \mathrm{~d}$ strength is between one-tenth and one-fourth the strength at $28 \mathrm{~d}$. Strength development in AAF concrete is even slower; the strength after $3 \mathrm{~d}$ is only one-fifth the $28 \mathrm{~d}$ compressive strength. Strength development in AAC cured at elevated temperature was much more rapid. In AASC concrete, the compressive strength after $48 \mathrm{~h}$ heat-curing was approximately equal to the 28-d ambient-cured strength. AAF concrete develops approximately double the $28 \mathrm{~d}$ ambient-cured compressive strength after heat-curing for $48 \mathrm{~h}$. In both cases, about 75 percent of that strength was developed in the first 24 hours.

Strength development is mostly a function of activation kinetics, which have been described in great detail by a number of studies [12, 82 84]. The activation reaction is greatly accelerated at elevated temperature and with increased sodium oxide dosage in the activator [12, 83, 84]. The reaction 
Table 4: Compressive strength $f_{c}^{\prime}$ and dynamic modulus of elasticity $E_{d}$ under various curing conditions

\begin{tabular}{|c|cc|ccc|ccc|}
\hline & & & \multicolumn{3}{|c|}{$f_{c}^{\prime}(\mathrm{MPa}[\mathrm{psi}])$} & \multicolumn{3}{|c|}{$E_{d}\left(\mathrm{GPa}\left[10^{6} \mathrm{psi}\right]\right)$} \\
& $\% \mathrm{Na}_{2} \mathrm{O}$ & $m$ & $28-\mathrm{d}\left(f_{c}^{\prime *}\right)$ & $90-\mathrm{d}$ & Heat-cured & $28-\mathrm{d}\left(E_{d}^{*}\right)$ & $90-\mathrm{d}$ & Heat-cured \\
\hline $\mathrm{PC} 1$ & - & - & $39.5[5730]$ & $42.6[6180]$ & - & $33.2[4.81]$ & $36.7[5.32]$ & - \\
\hline $\mathrm{FC} 1$ & 4.0 & 1.5 & $16.2[2350]$ & $22.5[3260]$ & $31.5[4570]$ & $18.1[2.62]$ & $21.4[3.10]$ & $17.9[2.60]$ \\
$\mathrm{FC} 2$ & 5.0 & 1.5 & $22.9[3320]$ & $26.4[3830]$ & $47.7[6920]$ & $22.4[3.25]$ & $25.3[3.67]$ & $21.2[3.07]$ \\
$\mathrm{FC} 3$ & 6.0 & 1.5 & $28.9[4190]$ & $33.4[4840]$ & $50.3[7290]$ & $23.9[3.47]$ & $26.7[3.87]$ & $26.4[3.83]$ \\
\hline $\mathrm{SC} 1$ & 4.0 & 1.5 & $41.2[5970]$ & $43.6[6320]$ & $39.7[5760]$ & $34.9[5.06]$ & $35.7[5.18]$ & $33.5[4.86]$ \\
$\mathrm{SC} 2$ & 5.0 & 1.5 & $46.2[6700]$ & $49.1[7120]$ & $46.6[6760]$ & $37.1[5.38]$ & $39.2[5.68]$ & $35.6[5.16]$ \\
$\mathrm{SC} 3$ & 4.0 & 0.75 & $33.7[4890]$ & $36.2[5250]$ & $29.5[4280]$ & $31.8[4.61]$ & $32.1[4.65]$ & $32.1[4.65]$ \\
$\mathrm{SC} 4$ & 5.0 & 0.75 & $44.7[6480]$ & $46.3[6710]$ & $44.0[6380]$ & $33.5[4.86]$ & $34.6[5.02]$ & $31.4[4.55]$ \\
$\mathrm{SC} 5$ & 6.0 & 0.75 & $46.7[6770]$ & $48.5[7030]$ & $45.6[6610]$ & $36.2[5.25]$ & $38.3[5.55]$ & $35.7[5.18]$ \\
\hline
\end{tabular}

is slightly retarded by increased silica in the activator, but the compressive strength at later age is generally improved [12, 83, 84].

The compressive strengths of AAC and PCC are presented in Table 5 for specimens dried at early age, later age, and after heat-curing. The relative compressive strength $f_{c}^{\prime} / f_{c}^{\prime *}$ and dynamic modulus $E_{d} / E_{d}^{*}$, where $f_{c}^{\prime *}$ and $E_{d}^{*}$ are the moist-cured compressive strength and dynamic modulus of elasticity, respectively, and $f_{c}^{\prime}$ and $E_{d}$ are the compressive strength and dynamic modulus of elasticity, respectively, after drying at either early or late age, are shown in Figure 8. This figure shows the strength and modulus reductions that resulted from drying under each condition. The strength and dynamic modulus in PCC of elasticity were only slightly reduced by drying at either early or later ages. When dried at early age, PCC retained about 85 percent of the $28 \mathrm{~d}$ strength. Meanwhile, AAC dried at early age exhibited about half the 28-d moist-cured compressive strength. That was accompanied by a reduction in dynamic modulus of 20-30 percent, which indicates extensive 


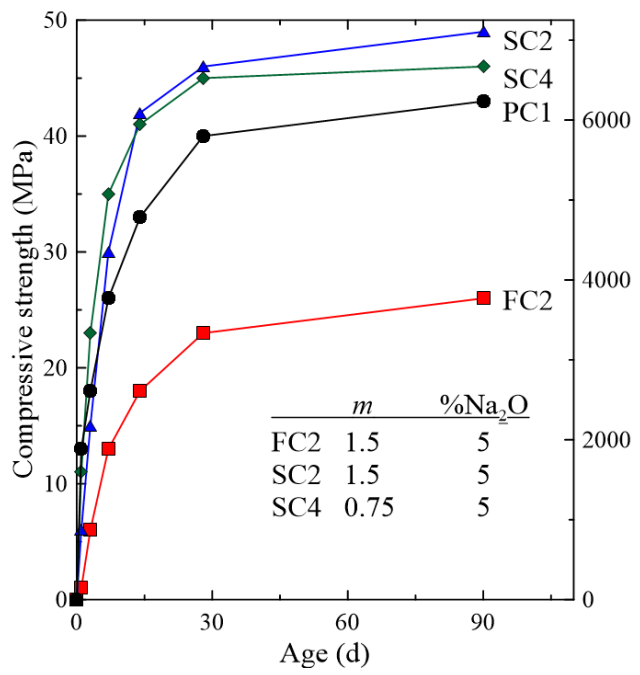

(a) Moist-cured at $23{ }^{\circ} \mathrm{C}$

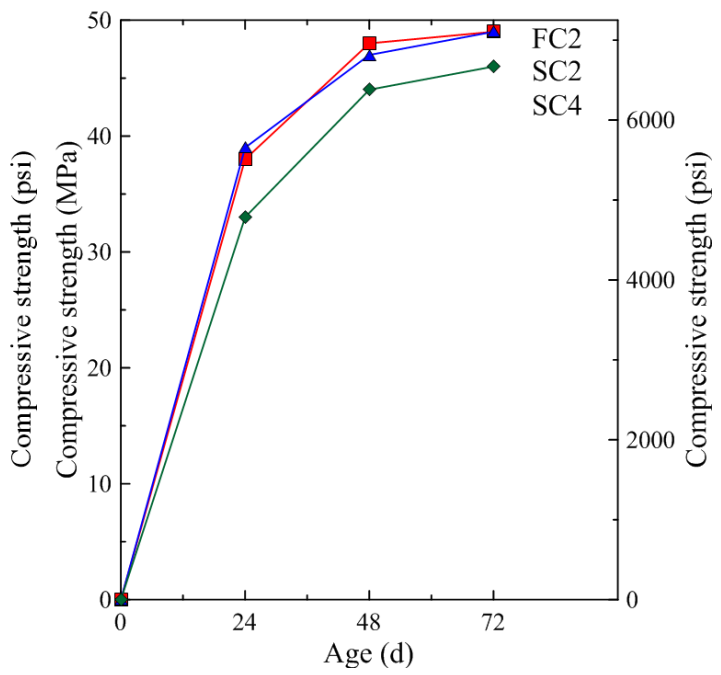

(b) Heat-cured at $50{ }^{\circ} \mathrm{C}$

Figure 7: Compressive strength development of selected concrete mixtures cured at ambient and elevated temperature

cracking. The reductions in strength and dynamic modulus in AAC were tempered at late age and after heat-curing. In most cases, the strength and dynamic modulus were very near the $28 \mathrm{~d}$ values when dried at late age or after heat curing. The strength of AAF concrete dried after heat-curing was much higher than the $28 \mathrm{~d}$ strength due to the dramatic effect of heat-curing on the compressive strength of AAF concrete. This shows that aging and heat-curing not only effectively mitigate the manifestation of drying shrinkage in AAC, but also effectively mitigate the associated damage. 
Table 5: Compressive strength $f_{c}^{\prime}$ and dynamic modulus of elasticity $E_{d}$ after $90 \mathrm{~d}$ drying with various curing conditions

\begin{tabular}{|l|ccc|ccc|}
\hline & \multicolumn{3}{|c|}{$f_{c}^{\prime}(\mathrm{MPa},[\mathrm{psi}])$} & \multicolumn{3}{c|}{$E_{d}\left(\mathrm{GPa}\left[10^{6} \mathrm{psi}\right]\right)$} \\
\hline & Early age & Late age & Heat-cured & Early age & Late age & Heat-cured \\
\hline PC1 & $33.7[4890]$ & $37.6[5450]$ & - & $32.0[4.64]$ & $34.1[4.94]$ & - \\
FC2 & $13.5[1960]$ & $19.2[2780]$ & $41.4[6000]$ & $11.5[1.67]$ & $20.9[3.03]$ & $19.9[2.89]$ \\
SC2 & $21.4[3100]$ & $42.3[6130]$ & $44.5[6450]$ & $29.3[4.25]$ & $37.6[5.45]$ & $33.1[4.80]$ \\
SC4 & $22.6[3280]$ & $41.4[6000]$ & $43.8[6350]$ & $28.8[4.18]$ & $33.2[4.81]$ & $30.0[4.35]$ \\
\hline
\end{tabular}

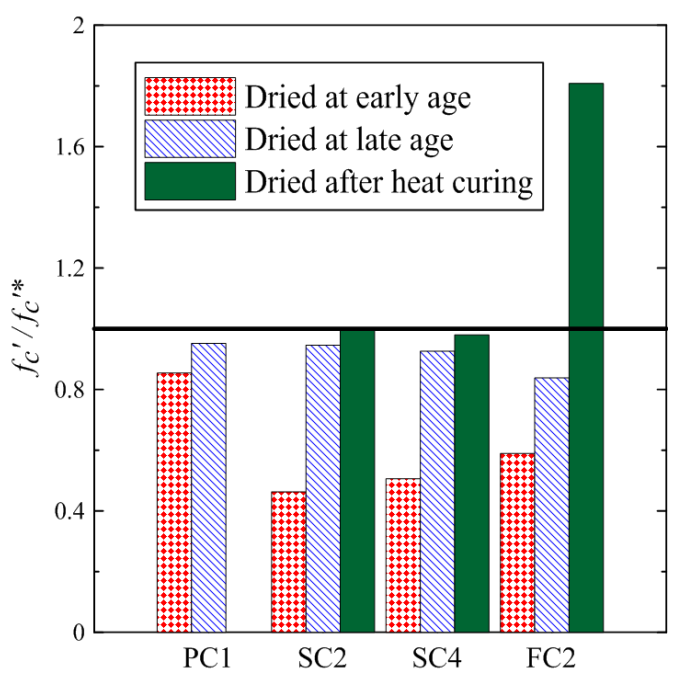

(a) $f_{c}^{\prime}$

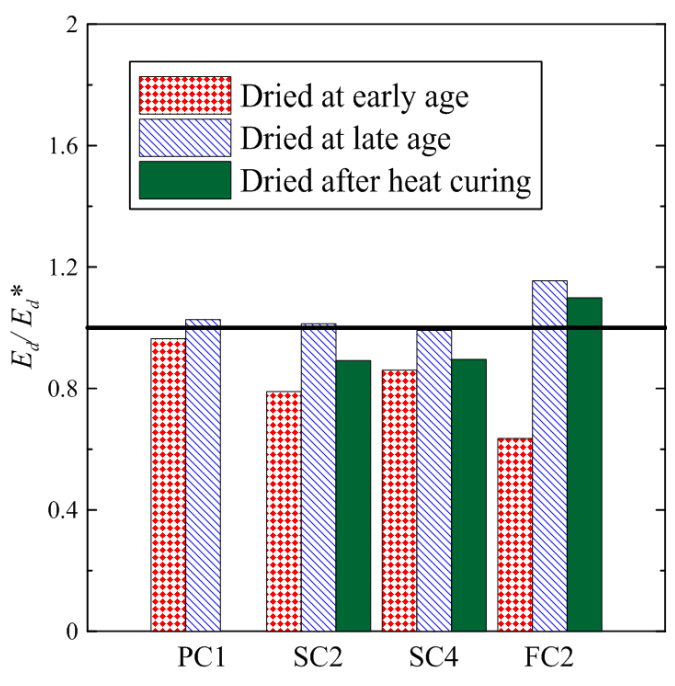

(b) $E_{d}$

Figure 8: Compressive strength $f_{c}^{\prime}$ and dynamic modulus of elasticity $E_{d}$ after drying relative to 28-d moist-cured compressive strength $f_{c}^{\prime *}$ and dynamic modulus of elasticity $E_{d}^{*}$

\section{Conclusions}

The drying shrinkage characteristics of AAF and AASC concrete under various conditions were investigated. The effects of activator concentration, 
heat-curing, and age were evaluated. The shrinkage characteristics of AAC were compared with those of PCC. Several interesting conclusions are drawn.

$\mathrm{AAC}$ is in general less volumetrically stable and more prone to damage than PCC under normal testing conditions (i.e., cured at ambient temperature and exposed to drying environment at early age). The magnitude of early-age drying shrinkage is sometimes in excess of $1000 \mu \varepsilon$ (0.1 percent strain). In AASC concrete, this results from a finer pore structure which greatly increases capillary stress. The dimensional stability of AASC concrete is, in turn, more sensitive to water loss. In AAF concrete, this is a result of higher total porosity which increases the pore volume and water loss. This shrinkage is accompanied by a strength loss of nearly 50 percent compared to the $28 \mathrm{~d}$ moist-cured strength.

The volumetric stability of AAC is greatly improved at later age. The drying shrinkage is reduced by two-thirds or more. The resulting damage is similarly tempered. When heat-cured, the volumetric stability is further improved. The magnitude of drying shrinkage is reduced by 75 percent or more, and the resulting damage is again reduced. Therefore, while AAC is highly susceptible to drying shrinkage at early age, the problem is easily mitigated without the use of chemical admixtures. This results from reductions in total porosity at later age and after heat-curing. This suggests that the poor early-age dimensional stability of AAC under drying conditions results mainly from delayed product formation and microstructure development.

In AAF concrete, an increase in sodium oxide concentration led to a reduction in the observed shrinkage. This is likely a result of reduced porosity and improved strength and stiffness. In AASC concrete, increases in both 
sodium oxide and silica modulus led to increased shrinkage, despite improving the strength. This could be due to a reduction in the porosity or an increase in pore fineness, which affect the sensitivity to water loss.

In general, the susceptibility of AAC to early-age drying shrinkage limits its applicability in the field. However, the effective mitigation of that shrinkage by either curing for a longer duration or at elevated temperature is summarily proven. These curing regimes are obvious unrealistic in-situ. However, a practical interpretation of these results is that AAC may be particularly well-suited for precast applications wherein these curing regimes are not necessarily prohibitive.

\section{Acknowledgment}

The authors gratefully acknowledge the financial support of the University Transportation Research Center, Region 2 (UTRC2) through the University Transportation Centers program and the National Science Foundation (NSF) under CMMI Award No. 1055641. Any opinions, findings, conclusions, or recommendations expressed in this article are those of the authors and do not necessarily reflect the views of UTRC2 or NSF.

\section{References}

[1] L K Turner and F G Collins. Carbon dioxide equivalent $\left(\mathrm{CO}_{2}\right.$-e $)$ emissions: A comparison between geopolymer and OPC cement concrete. Construction and Building Materials, 43:125-130, 2013.

[2] P Duxson, J L Provis, G C Lukey, and J S J Van Deventer. The role 
of inorganic polymer technology in the development of green concrete. Cement and Concrete Research, 37(12):1590-1597, 2007.

[3] B C McLellan, R P Williams, J Lay, A Van Riessen, and G D Corder. Costs and carbon emissions for geopolymer pastes in comparison to ordinary portland cement. Journal of Cleaner Production, 19(9):1080-1090, 2011.

[4] G Habert, J B DEspinose De Lacaillerie, and N Roussel. An environmental evaluation of geopolymer based concrete production: Reviewing current research trends. Journal of Cleaner Production, 19(11):1229$1238,2011$.

[5] J S J Van Deventer, J L Provis, and P Duxson. Technical and commercial progress in the adoption of geopolymer cement. Minerals Engineering, 29:89-104, 2012.

[6] K H Yang, J K Song, and K I Song. Assessment of $\mathrm{CO}_{2}$ reduction of alkali-activated concrete. Journal of Cleaner Production, 39:265-272, 2013.

[7] A Mellado, C Catalán, N Bouzón, M V Borrachero, J M Monzó, and J Payá. Carbon footprint of geopolymeric mortar: study of the contribution of the alkaline activating solution and assessment of an alternative route. RSC Advances, 4(45):23846-23852, 2014.

[8] H Kuhl. Slag cement and process of making the same. 1908. US Patent 900,939 . 
[9] A O Purdon. The action of alkalis on blast-furnace slag. Journal of the Society of Chemical Industry, 59:191-202, 1940.

[10] V D Glukhovsky. Soil silicate articles and structures. Budivelnyk, Kiev, 1967.

[11] J Davidovits and J L Sawyer. Early high-strength mineral polymer. 1985. US Patent $4,509,985$.

[12] R J Thomas, H Ye, A Radliǹska, and S Peethamparan. Alkali-activated slag cement concrete. Concrete International, 38(1):33-38, 2016.

[13] K Byfors, G Klingstedt, V Lehtonen, H Pyy, and L Romben. Durability of concrete made with alkali-activated slag. Special Publication, 114: 1429-1466, 1989.

[14] E Douglas, A Bilodeau, and V M Malhotra. Properties and durability of alkali-activated slag concrete. ACI Materials Journal, 89(5):509-516, 1992.

[15] T Bakharev, J G Sanjayan, and Y-B Cheng. Resistance of alkaliactivated slag concrete to alkali-aggregate reaction. Cement and Concrete Research, 31(2):331-334, 2001.

[16] T Bakharev, J G Sanjayan, and Y-B Cheng. Resistance of alkaliactivated slag concrete to carbonation. Cement and Concrete Research, 31(9):1277-1283, 2001.

[17] T Bakharev, J G Sanjayan, and Y-B Cheng. Sulfate attack on alkali- 
activated slag concrete. Cement and Concrete Research, 32(2):211-216, 2002.

[18] T Bakharev, J G Sanjayan, and Y-B Cheng. Resistance of alkaliactivated slag concrete to acid attack. Cement and Concrete Research, 33(10):1607-1611, 2003.

[19] A Al-Otaibi. Durability of concrete incorporating ggbs activated by water-glass. Construction and Building materials, 22(10):2059-2067, 2008.

[20] A A Adam. Strength and durability properties of alkali activated slag and fly ash-based geopolymer concrete. PhD thesis, RMIT University Melbourne, Australia, 2009.

[21] M Chi. Effects of dosage of alkali-activated solution and curing conditions on the properties and durability of alkali-activated slag concrete. Construction and Building Materials, 35:240-245, 2012.

[22] S A Bernal and J L Provis. Durability of alkali-activated materials: Progress and perspectives. Journal of the American Ceramic Society, 97(4):997-1008, 2014.

[23] F Pacheco-Torgal, Z Abdollahnejad, A F Camões, M Jamshidi, and Y Ding. Durability of alkali-activated binders: A clear advantage over portland cement or an unproven issue? Construction and Building Materials, 30:400-405, 2012.

[24] J L Provis, A Palomo, and C Shi. Advances in understanding alkaliactivated materials. Cement and Concrete Research, 78:110-125, 2015. 
[25] K Arbi, M Nedeljkovic, Y Zuo, and G Ye. A review on the durability of alkali-activated fly ash/slag systems: Advances, issues, and perspectives. Industrial \& Engineering Chemistry Research, 55(19):5439-5453, 2016.

[26] Z P Bažant. Prediction of concrete creep and shrinkage: past, present and future. Nuclear Engineering and Design, 203(1):27-38, 2001.

[27] M Y Han and R L Lytton. Theoretical prediction of drying shrinkage of concrete. Journal of Materials in Civil Engineering, 7(4):204-207, 1995.

[28] B Bissonnette, P Pierre, and M Pigeon. Influence of key parameters on drying shrinkage of cementitious materials. Cement and Concrete Research, 29(10):1655-1662, 1999.

[29] T C Powers and T L Brownyard. Studies of the physical properties of hardened portland cement paste. Bulletin, 22, 1946.

[30] P C Aitcin, A Neville, and P Acker. Integrated view of shrinkage deformation. Concrete International, 19(9):35-41, 1997.

[31] O M Jensen and P F Hansen. Water-entrained cement-based materials I: Principles and theoretical background. Cement and Concrete Research, 31(4):647-654, 2001.

[32] M Rö $\beta$ ler and I Odler. Investigations on the relationship between porosity, structure and strength of hydrated portland cement pastes i. effect of porosity. Cement and Concrete Research, 15(2):320-330, 1985.

[33] B Mather and W G Hime. Amount of water required for complete hydration of portland cement. Concrete international, 24(6):56-58, 2002. 
[34] T C Powers. Structure and physical properties of hardened portland cement paste. Journal of the American Ceramic Society, 41(1):1-6, 1958.

[35] R F Feldman and P J Sereda. A model for hydrated portland cement paste as deduced from sorption-length change and mechanical properties. Matériaux et Construction, 1(6):509-520, 1968.

[36] T C Powers. The thermodynamics of volume change and creep. Matériaux et Construction, 1(6):487-507, 1968.

[37] Z P Bažant and L J Najjar. Nonlinear water diffusion in nonsaturated concrete. Matériaux et Construction, 5(1):3-20, 1972.

[38] Z P Bažant. Thermodynamics of hindered adsorption and its implications for hardened cement paste and concrete. Cement and Concrete Research, 2(1):1-16, 1972.

[39] N K Becker and C MacInnis. A theoretical method for predicting the shrinkage of concrete. Journal of the American Concrete Institute, 70 (9):652-657, 1973.

[40] F H Wittmann. Interaction of hardened cement paste and water. Journal of the American Ceramic Society, 56(8):409-415, 1973.

[41] W Hansen. Drying shrinkage mechanisms in portland cement paste. Journal of the American Ceramic Society, 70(5):323-328, 1987.

[42] D H Bangham and RI Razouk. Adsorption and the wettability of solid surfaces. Transactions of the Faraday Society, 33:1459-1463, 1937. 
[43] D H Bangham. The Gibbs adsorption equation and adsorption on solids. Transactions of the Faraday Society, 33:805-811, 1937.

[44] P K Mehta and P J M Monteiro. Concrete structures, properties and materials. 1993.

[45] C F Ferraris and F H Wittmann. Shrinkage mechanisms of hardened cement paste. Cement and Concrete Research, 17(3):453-464, 1987.

[46] Z P Bažant, A B Hauggaard, S Baweja, and F J Ulm. Microprestresssolidification theory for concrete creep I: Aging and drying effects. Journal of Engineering Mechanics, 123(11):1188-1194, 1997.

[47] F Beltzung and F H Wittmann. Role of disjoining pressure in cement based materials. Cement and Concrete Research, 35(12):2364-2370, 2005.

[48] R M Espinosa and L Franke. Influence of the age and drying process on pore structure and sorption isotherms of hardened cement paste. Cement and Concrete Research, 36(10):1969-1984, 2006.

[49] Z P Bažant and S Baweeja. Rilem draft recommendation: Creep and shrinkage prediction model for analysis and design of concrete structures. Materials and Structures, 28:357-365, 1995.

[50] H M Jennings and P D Tennis. Model for the developing microstructure in portland cement pastes. Journal of the American Ceramic Society, 77(12):3161-3172, 1994. 
[51] P D Tennis and H M Jennings. A model for two types of calcium silicate hydrate in the microstructure of portland cement pastes. Cement and Concrete Research, 30(6):855-863, 2000.

[52] A J Hurd and S M Rao. Silica aerogel films prepared at ambient pressure by using surface derivatization to induce reversible drying shrinkage. Nature, 374:30, 1995.

[53] V Slowik, M Schmidt, and R Fritzsch. Capillary pressure in fresh cement-based materials and identification of the air entry value. $\mathrm{Ce}$ ment and Concrete Composites, 30(7):557-565, 2008.

[54] F Collins and J G Sanjayan. Strength and shrinkage properties of alkaliactivated slag concrete containing porous coarse aggregate. Cement and Concrete Research, 29(4):607-610, 1999.

[55] T Bakharev, J G Sanjayan, and Y-B Cheng. Effect of elevated temperature curing on properties of alkali-activated slag concrete. Cement and Concrete Research, 29(10):1619-1625, 1999.

[56] F Collins and J G Sanjayan. Cracking tendency of alkali-activated slag concrete subjected to restrained shrinkage. Cement and Concrete Research, 30(5):791-798, 2000.

[57] T Bakharev, J G Sanjayan, and Y-B Cheng. Effect of admixtures on properties of alkali-activated slag concrete. Cement and Concrete Research, 30(9):1367-1374, 2000. 
[58] F Collins and J G Sanjayan. Effect of pore size distribution on drying shrinking of alkali-activated slag concrete. Cement and Concrete Research, 30(9):1401-1406, 2000.

[59] M Palacios and F Puertas. Effect of shrinkage-reducing admixtures on the properties of alkali-activated slag mortars and pastes. Cement and Concrete Research, 37(5):691-702, 2007.

[60] A A M Neto, M A Cincotto, and W Repette. Drying and autogenous shrinkage of pastes and mortars with activated slag cement. Cement and Concrete Research, 38(4):565-574, 2008.

[61] C D Atiş, C Bilim, Ö Çelik, and O Karahan. Influence of activator on the strength and drying shrinkage of alkali-activated slag mortar. Construction and Building Materials, 23(1):548-555, 2009.

[62] AR Sakulich and D P Bentz. Mitigation of autogenous shrinkage in alkali activated slag mortars by internal curing. Materials and Structures, 46 (8):1355-1367, 2013.

[63] C Shi. Strength, pore structure and permeability of alkali-activated slag mortars. Cement and Concrete Research, 26(12):1789-1799, 1996.

[64] F Collins and J G Sanjayan. Microcracking and strength development of alkali activated slag concrete. Cement and Concrete Composites, 23 (4):345-352, 2001.

[65] W Chen and H J H Brouwers. The hydration of slag, Part 1: Reaction models for alkali-activated slag. Journal of Materials Science, 42(2): 428-443, 2007. 
[66] A M Fernández-Jiménez, A Palomo, and C Lopez-Hombrados. Engineering properties of alkali-activated fly ash concrete. ACI Materials Journal, 103(2):106-112, 2006.

[67] D Hardjito, S E Wallah, D M J Sumajouw, and B V Rangan. On the development of fly ash-based geopolymer concrete. ACI Materials Journal, 101(6):467-472, 2004.

[68] SE Wallah and B V Rangan. Low-calcium fly ash-based geopolymer concrete: Long-term properties. Technical report, Curtin University, 2006.

[69] M Chi and R Huang. Binding mechanism and properties of alkaliactivated fly ash/slag mortars. Construction and Building Materials, 40:291-298, 2013.

[70] J L Provis, R J Myers, C E White, V Rose, and J S J van Deventer. X-ray microtomography shows pore structure and tortuosity in alkaliactivated binders. Cement and Concrete Research, 42(6):855-864, 2012.

[71] R R Lloyd, J L Provis, K J Smeaton, and J S J van Deventer. Spatial distribution of pores in fly ash-based inorganic polymer gels visualised by woods metal intrusion. Microporous and Mesoporous Materials, 126 (1):32-39, 2009.

[72] C A Leon y Leon. New perspectives in mercury porosimetry. Advances in colloid and interface science, 76:341-372, 1998.

[73] S Diamond. Mercury porosimetry: an inappropriate method for the 
measurement of pore size distributions in cement-based materials. Cement and concrete research, 30(10):1517-1525, 2000.

[74] S Brunauer, P H Emmett, and E Teller. Adsorption of gases in multimolecular layers. Journal of the American chemical society, 60(2): 309-319, 1938.

[75] A M Fernández-Jiménez and A Palomo. Characterisation of fly ashes. potential reactivity as alkaline cements. Fuel, 82(18):2259-2265, 2003.

[76] G Kovalchuk, A Fernández-Jiménez, and A Palomo. Alkali-activated fly ash: effect of thermal curing conditions on mechanical and microstructural development-part ii. Fuel, 86(3):315-322, 2007.

[77] F Škvára, L Kopeckỳ, V Šmilauer, and Z Bittnar. Material and structural characterization of alkali activated low-calcium brown coal fly ash. Journal of Hazardous Materials, 168(2):711-720, 2009.

[78] Y Ma, J Hu, and G Ye. The pore structure and permeability of alkali activated fly ash. Fuel, 104:771-780, 2013.

[79] Sindhunata, J S J Van Deventer, GC Lukey, and H Xu. Effect of curing temperature and silicate concentration on fly-ash-based geopolymerization. Industrial \& Engineering Chemistry Research, 45(10):3559-3568, 2006.

[80] F Collins and J Sanjayan. Unsaturated capillary flow within alkali activated slag concrete. Journal of Materials in Civil Engineering, 20(9): 565-570, 2008. 
[81] F G Collins and J G Sanjayan. Capillary shape: influence on water transport within unsaturated alkali activated slag concrete. Journal of Materials in Civil Engineering, 22(3):260-266, 2010.

[82] E Deir, B S Gebregziabiher, and S Peethamparan. Influence of starting material on the early age hydration kinetics, microstructure and composition of binding gel in alkali activated binder systems. Cement and Concrete Composites, 48:108-117, 2014.

[83] B S Gebregziabiher, R J Thomas, and S Peethamparan. Very earlyage reaction kinetics and microstructural development in alkali-activated slag. Cement and Concrete Composites, 55:91-102, 2015.

[84] B S Gebregziabiher, R J Thomas, and S Peethamparan. Temperature and activator effects on early-age reaction kinetics of alkali-activated slag binders. Construction and Building Materials, 113:783-793, 2016.

[85] A R Brough and A Atkinson. Sodium silicate-based, alkali-activated slag mortars: Part I. Strength, hydration and microstructure. Cement and Concrete Research, 32(6):865-879, 2002.

[86] R J Thomas and S Peethamparan. Alkali-activated concrete: Engineering properties and stress-strain behavior. Construction and Building Materials, 93:49-56, 2015.

[87] D Krizan and B Zivanovic. Effects of dosage and modulus of water glass on early hydration of alkali-slag cements. Cement and Concrete Research, 32(8):1181-1188, 2002. 
[88] F Pacheco-Torgal, J Castro-Gomes, and S Jalali. Alkali-activated binders: A review: Part 1. historical background, terminology, reaction mechanisms and hydration products. Construction and Building Materials, 22(7):1305-1314, 2008.

[89] M B Haha, G Le Saout, F Winnefeld, and B Lothenbach. Influence of activator type on hydration kinetics, hydrate assemblage and microstructural development of alkali activated blast-furnace slags. Cement and Concrete Research, 41(3):301-310, 2011.

[90] E Altan and S T Erdoğan. Alkali activation of a slag at ambient and elevated temperatures. Cement and Concrete Composites, 34(2):131139, 2012.

[91] M Criado, A Palomo, and A Fernández-Jiménez. Alkali activation of fly ashes. part 1: Effect of curing conditions on the carbonation of the reaction products. Fuel, 84(16):2048-2054, 2005.

[92] F Puertas, M Palacios, and T Vázquez. Carbonation process of alkaliactivated slag mortars. Journal of Materials Science, 41(10):3071-3082, 2006.

[93] C Shi, D Roy, and P Krivenko. Alkali-activated cements and concretes. CRC press, 2006.

[94] R J Thomas. Properties and Performance of Alkali-Activated Concrete. PhD thesis, Clarkson University, 2016. 
${ }_{756}$ [95] R J Thomas and S Peethamparan. Modified test for chloride permeability of alkali-activated concrete. In Proceedings of the 95th Annual Meeting of the Transportation Research Board, number 16-5098, 2016.

[96] S S Park and H Y Kang. Strength and microscopic characteristics of alkali-activated fly ash-cement. Korean Journal of Chemical Engineering, 23(3):367-373, 2006. 